\title{
The role of necroptosis in neurosurgical diseases
}

\author{
T. Liu, Y.H. Bao, Y. Wang and J.Y. Jiang
}

Department of Neurosurgery, Ren Ji Hospital, School of Medicine, Shanghai Jiaotong University, Shanghai, China

\begin{abstract}
Programmed necrosis or necroptosis is an alternative form of cell death that is executed through a caspase-independent pathway. Necroptosis has been implicated in many pathological conditions. Genetic or pharmacological inhibition of necroptotic signaling has been shown to confer neuroprotection after traumatic and ischemic brain injury. Therefore, the necroptotic pathway represents a potential target for neurological diseases that are managed by neurosurgeons. In this review, we summarize recent advances in the understanding of necroptotic signaling pathways and explore the role of necroptotic cell death in craniocerebral trauma, brain tumors, and cerebrovascular diseases.
\end{abstract}

Key words: Molecular mechanism; Pathogenesis; Programmed cell death; Therapy

\section{Introduction}

The two basic forms of cell death, necrosis and apoptosis, play essential roles in development, homeostasis, and pathogenesis (1). Necrosis has long been considered an uncontrolled form of cell death, with morphological features of loss of plasma membrane integrity, organelle swelling, and leakage of cell contents. In contrast, apoptosis is a tightly regulated form of cell death characterized by nuclear shrinkage and fragmentation, membrane blebbing, and apoptotic body formation. However, growing evidence has described an active and well-orchestrated form of necrosis, termed necroptosis (2). Numerous cellular stimuli (e.g., tumor necrosis factor [TNF], Fas ligand, TNF-related apoptosis inducing ligand [TRAIL], double-stranded RNA, interferon- $\gamma$, ATP depletion, ischemia-reperfusion injury, and pathogens) have been shown to induce necroptosis (3). Compared to apoptotic cells, necroptotic cells have distinct features that are not induced by the caspase activation that is typically required for apoptotic death (4). However, there are no specific biochemical markers for necroptosis. It has become clear that the kinase receptor interacting protein 1 (RIP1) participates in regulating both necroptosis and apoptosis (5). When apoptotic cell death is blocked by pancaspase inhibitors, death signals such as Fas ligand and TNF can trigger necroptosis as an alternative cell death pathway (5). RIP1 kinase activity is also crucial for this alternative death pathway (6). It has been documented that the allosteric RIP1 kinase inhibitor (necrostatin-1) inhibits death receptor-induced necroptosis in various cellular models, indicating the essential role of RIP1 activity in necroptotic signaling (5). In addition to RIP1, RIP3 kinase activity has also been implicated in this caspase-independent mode of cell death (7). Indeed, using genetically engineered mice expressing a kinase-inactive mutant of RIP3, Newton et al. (8) found that necroptosis was blocked in the whole animal. These findings support a mediating role of RIP kinases in necroptotic cell death.

Necroptosis is involved in many pathological processes (9-11). It contributes to ischemia-reperfusion injury in the kidney, heart, and brain (12). Necroptosis has also been shown to participate in pathogen- or injury-induced inflammatory diseases (13). The necroptotic pathway therefore constitutes a potential target for preventing cell death. Indeed, chemical inhibition of necroptosis with necrostatin-1 or necrostatin- 5 has been shown to confer cardioprotective effects on the isolated rat heart subjected to global ischemiareperfusion (14). Similarly, inhibition of necroptosis with necrostatin-1 was found to attenuate myocardial ischemiareperfusion injury in isolated guinea pig hearts (15). In the pathogenesis of neurosurgical diseases (e.g., craniocerebral trauma, brain tumor, and cerebrovascular diseases), necroptosis also plays a critical role. Li et al. (16) reported that necroptosis contributes to the N-methyl-D-aspartate (NMDA)-induced excitotoxicity in isolated rat cortical neurons. Yamanaka et al. (17) reported that necroptosis mediates 24(S)-hydroxycholesterol-induced neuronal cell death. In vivo animal studies revealed that administration of the necroptosis inhibitor necrostatin-1 delayed mouse ischemic brain injury (18). Injection of necrostatin-1 has protective

Correspondence: Yinghui Bao: <bombbao@126.com>.

Received August 11, 2014. Accepted November 13, 2014. First published online February 24, 2015. 
effects against neurovascular injury secondary to intracerebral hemorrhage $(\mathrm{ICH})$ in a mouse model (19). Collectively, these studies suggest that necroptosis represents an attractive therapeutic target for a broad range of diseases. Therefore, understanding necroptotic signaling machinery has clinical relevance.

\section{The death receptor pathway for necroptosis}

Necroptosis is generally activated by ligation of death receptors including Fas, TNF-receptor 1 (TNFR1), TNFR2, TRAIL receptor 1 (TRAILR1), and TRAILR2 (6). These death receptors were originally recognized to initiate apoptotic death. TNF is the inducer of necroptosis that has been most studied (20). Depending on cell type, TNF administration may trigger apoptosis or necroptosis (21), which suggests a complex signal mechanism in cell death regulation. TNFR1 can be activated by TNF through the pre-ligand assembly domain of the Cys-rich domain 1 in the extracellular portion of TNFR1. The activated TNFR1 subsequently forms a trimer that enables its intracellular part to recruit various proteins, such as TNFR-associated death domain (TRADD), RIP1, cellular inhibitor of apoptosis 1 (cIAP1), cIAP2, TNFRassociated factor 2 (TRAF2), and TRAF5 (22). As E3 ubiquitin ligases, clAPs catalyze the addition of Lys63-linked polyubiquitin moieties of RIP1, which subsequently provide three docking sites for transforming growth factor- $\beta$-activated kinase 1 (TAK1), TAK1-binding protein 2 (TAB2), and TAB3 to constitute the TAK1-TAB2-TAB3 complex, leading to the activation of nuclear factor (NF)- $\kappa B$ and transactivation of cytoprotective genes such as cellular FLICE-like inhibitory protein (c-FLIP). clAP-mediated ubiquitination of RIP1 prevents RIP1 from integrating and activating death complexes, impairing caspase activation (23). TAK1 knockout leads to the propensity of cells to undergo necroptosis (24). However, several lines of evidence demonstrate that prolonged and excessive activation of TAK1 induces phosphorylation and activation of RIP3, leading to necroptosis even without TNF stimulation, whereas ablation of TAK1 causes caspase-dependent apoptosis (25). Therefore, TAK1 may act as a common upstream regulator of both apoptosis and necroptosis. RIP1 can be deubiquitylated by the Lys63-deubiquitylating enzyme cylindromatosis (CYLD) (26) and form a complex with TRADD, FAS-associated death domain protein (FADD), and caspase-8 (i.e., the death-inducing signaling complex [DISC]) (27). Activation of caspase- 8 in the DISC is believed to initiate the proapoptotic caspase cascade (28). However, it remains unclear whether FADD and TRADD are required to assemble the necroptosis-signaling complex, or "necrosome." When caspase- 8 activity is genetically or pharmacologically inhibited, the RIP1-RIP3 complex activates necroptotic signaling (29), and necrosome assembly is required for necroptosis. A recent study has demonstrated that the guanine nucleotide-binding protein $\gamma 10$ gene is involved in TNF-induced necroptosis via promotion of necrosome translocation (29).
RIP1, a 74-kDa protein, contains an N-terminal Ser/Thr kinase, an intermediate domain containing a RIP homotypic interaction motif (RHIM) that binds to the RHIM in RIP3 and a C-terminal death domain (30). The C-terminal domain of RIP1 mediates the interaction of RIP1 with Fas and other DD-containing proteins. RIP1 is a pivotal component of the DISC complex and plays a pivotal role in cell-fate decision (30). Since necrostatin-1 was identified as a small-molecule inhibitor of RIP1 by Degterev et al. (18), it has been widely used to study the molecular mechanisms of necroptosis. Shulga and Pastorino identified RIP1 as the mediator of signal transducer and activator of transcription 3 (STAT3) Ser727 phosphorylation, which leads to the translocation of STAT3 into mitochondria (31). This finding provides insight into how RIP1 inhibits apoptosis but promotes necroptosis in the event of stroke (31). The RIP1 cognate kinase RIP3 can trigger necroptosis irrespective of the presence of RIP1, at least in some experimental scenarios. Infection with murine cytomegalovirus has also been observed to induce RIP3-dependent but RIP1-independent necroptosis (32), suggesting the importance of RIP3.

Narayan et al. (33) reported that SIRT2, one of the sirtuin family of proteins, plays a significant role in the initiation of necroptosis. They found that SIRT2 binds constitutively to RIP3 and forms the RIP3-SIRT2 complex, whereas SIRT2 deletion or knockdown prevents TNF-induced necroptosis in L929 cells. The suppression of necroptosis can also be detected after the administration of a specific SIRT2 deacetylase inhibitor (34). In contrast, addition of recombinant SIRT2 protein is sufficient to constitute the RIP1-RIP3 complex for deacetylation of RIP1 (33).

The interaction of RIP1 and RIP3 has been suggested to contribute to necrosome assembly via the RHIM, a hydrophobic patch of $\beta$ sheet (IQIGXXN for RIP1 [amino acids 539-542] and VQVGXXN for RIP3 [amino acids 458-461]) flanked by unstructured coiled-like residues (35). Mutations of the core RHIM residues of RIP1 (IQIG) or RIP3 (VQVG) impair necrosome formation and necroptotic cell death. These results suggest that the RIP kinase activities and necrosome assembly might function in a feed-forward manner to amplify the pronecrotic signal. Mixed lineage kinase domain-like protein (MLKL) has been identified as a mediator of RIP3-dependent necroptosis (36). MLKL can be phosphorylated by RIP3 at its threonine 357 and serine 358 residues, and these phosphorylation events are essential for necroptosis. Treating cells with necrosulfonamide or knocking down MLKL expression was found to arrest necroptosis (36). MLKL-deficient cells are resistant to TNFinduced necroptosis unless MLKL expression is restored, confirming the key role of MLKL in TNF-induced necroptosis (37). Structurally, MLKL comprises a four-helical bundle tethered to the pseudokinase domain that contains an unusual pseudoactive site. Mutation of the MLKL pseudoactive site leads to constitutive, RIPK3-independent necroptosis, indicating the importance of MLKL modification in the necroptosis pathway downstream of RIPK3 (37). 


\section{The toll-like receptor (TLR) pathway for necroptosis}

TLR signaling is triggered by pathogen-associated molecular patterns and plays a critical role in cytokine production. TLRs were found to induce RIP3-dependent necroptosis through either TIR domain-containing adapter induction of IFN-beta (TRIF) or myeloid differentiation primary response protein 88 (MyD88) signal transduction (38). In fibroblasts, activation of this pathway depends on MLKL downstream of RIP3 kinase. Kim and Li (39) reported that there is a close link between TLR signaling and RIP3dependent necroptosis in microglia. The deubiquitinase CYLD has been identified to be involved in TLR-induced necroptosis in macrophages from wild-derived MOLF mice (40).

\section{Execution of necroptosis}

Caspases are the agents of apoptosis; however, these proteases are not essential for necroptosis. Several downstream mediators of necroptosis have been identified. Reactive oxygen species (ROS) have been identified as agents of necroptosis. TNF stimulation leads to ROS production in multiple cell types (41). ROS activity is also linked to the oxidation of MAP kinase phosphatases (MKPs) whose normal function is to downregulate c-Jun $\mathrm{N}$ terminal kinase (JNK) pathway signaling (42). Excessive ROS results in prolonged JNK activation and subsequent cell death. Treatment with an antioxidant such as butylated hydroxyanisole $(\mathrm{BHA})$ is able to reduce ROS levels and also to inhibit cell death in some cell types (41). However, there are conflicting reports on the effect of ROS inhibition on necroptosis (18), suggesting that the ability of ROS to act as agents of necroptosis is likely to be a cell-type dependent phenomenon.

During apoptosis, ATP-consuming processes such as gene translation and proteasome-mediated degradation are rapidly shut off by caspases. In contrast, these processes persist during TNF-induced necroptosis, thereby leading to the lethal decline in intracellular ATP (43). Overactivation of poly-ADP-ribose polymerase 1 (PARP1), a nuclear enzyme involved in DNA repair and transcriptional regulation, may cause ATP depletion. PARP1 has been implicated in the necroptotic response of L929 fibrosarcoma cells to TNF (44). Mechanistically, PARP1 activation promotes the translocation of apoptosis-inducing factor (AIF) from the mitochondrial intermembrane space to the nuclear compartment, where it mediates large-scale, caspase-independent DNA fragmentation (45). Pharmacological and genetic inhibition of PARP1 or blockade of AIF expression has been found to protect cells against necroptotic stimuli (46). It has been documented that RIP1-deficient mouse embryonic fibroblast cells are resistant to PARP1induced cell death in response to DNA alkylating agents (47), suggesting that RIP1 activation occurs downstream of PARP1. Adenine nucleotide translocase (ANT) and cyclophilin $\mathrm{D}(\mathrm{CypD})$, which participate in the mitochondrial permeability transition, have been proposed to be involved in necroptosis. CypD ablation protects mice from ischemic renal injury via inhibition of ATP depletion (48). ANT has been suggested to interact with $\mathrm{CypD}$ and the voltagedependent anion channel (VDAC) to form the permeability transition pore complex (PTPC) (49). Pharmacological and genetic inhibition of the backbone components of the PTPC, including VDAC, ANT, and CYPD, exerts consistent cytoprotective effects against numerous insults in vitro and in vivo (50). These results underscore the importance of mitochondrial events in necroptosis.

Lysosomal membrane permeabilization (LMP) has been suggested as an early step in TNF-induced apoptosis (51). LMP is a potentially lethal event because the release of lysosomal proteases into the cytosol may cause digestion of vital proteins and activation of other hydrolases, especially caspases. LMP can be stimulated by a variety of distinct stimuli, including ROS, lysosomotropic compounds with detergent activity, and some endogenous cell death effectors. Extensive LMP often results in cell death without caspase activation. Indeed, LMP has been detected in necroptosis (52). Cytosolic phospholipase A2 (cPLA2) and ceramide act upstream of lipid peroxidation to stimulate LMP. It has been documented that CPLA2 overexpression sensitizes TNFresistant L929 cells to necroptosis (53). Ceramide is capable of triggering either apoptosis or necroptosis, depending on the specific experimental setting (54). cPLA2-deficient L929 cells fail to accumulate ceramide after TNF exposure and are protected against TNF-induced necroptosis, suggesting an essential role for CPLA2 in ceramide generation and consequent necroptotic cell death (55).

\section{Involvement of necroptosis in the pathogenesis of traumatic brain injury (TBI)}

TBI is a leading cause of death and disability worldwide. Emergency treatment of $\mathrm{TBI}$ is critical for reducing secondary insults. Decompressive craniectomy can immediately reduce intracranial pressure and has been used to treat patients with severe TBI and refractory intracranial hypertension (56). Hypothermia therapy has also been used to manage intracranial hypertension in patients with TBI (57). Cell death after TBI is regarded as a significant cause of disability and death worldwide. There is evidence showing that necroptosis plays a significant role in the pathogeneses of tissue damage and functional deficits after TBI (58). The necroptosis inhibitor necrostatin-1 has been shown to improve functional outcome after controlled cortical impact in mice (58). Previous studies have demonstrated that both Akt and mammalian target of rapamycin (mTOR) signaling are activated after TBI $(59,60)$. Akt is known as an inhibitor of apoptotic neuronal cell death, while mTOR is a downstream effector of Akt. A recent study reported that the combined inhibition of Akt and mTOR signaling reduces 
necrotic cell death in cornu ammonis (CA) 3 and CA1 regions of the hippocampus and improves functional outcome in mice subjected to controlled-cortical impact (61). Moreover, when concomitant treatment with TNF and zVAD (a caspase inhibitor) was administered to induce necroptosis in the hippocampal neuronal cell line HT22, cell death was preceded by RIPK1-RIPK3-pAkt assembly and phosphorylation of AKT and mTOR. Pretreatment with Akt and mTOR inhibitors suppressed mitochondrial ROS production and necroptosis, suggesting that Akt/mTOR activation causes necroptosis in neurons by inducing lethal oxidative stress (62). Therefore, inhibition of necroptosis may provide a promising therapeutic strategy for TBI.

\section{Necroptosis as a novel therapeutic target for brain tumors}

Glioblastoma is a highly aggressive and lethal brain tumor (63). Due to a lack of effective therapies, the prognosis of glioblastoma is very poor. A combination of surgery and radiation with or without chemotherapy is the primary treatment for malignant gliomas. Defects in apoptosis are believed to account for the resistance of brain tumors to radio- and chemotherapy. It has been suggested that there is a close relationship between necroptosis and apoptosis. Han et al. (64) reported that the inhibitor necrostatin-1 can revert shikonin (a component of Chinese herbal medicine)induced necroptosis to apoptosis. Huang et al. (65) showed that shikonin induces RIP1-dependent necroptosis in glioma cells. Hemagglutinating virus of Japan-envelope (HVJ-E) has been shown to induce necroptotic cell death in human neuroblastoma cells (66). Mechanistically, an increase in the cytoplasmic $\mathrm{Ca}^{2+}$ concentration triggers activation of $\mathrm{Ca}^{2+}$ calmodulin kinase (CaMK) II, consequently leading to RIP1 phosphorylation and ROS production. 5-Aminolevulinic acid-based photodynamic therapy (5-ALA-PDT) was found to induce necroptosis in glioblastoma cells when NF-KB had been inhibited (67). A derivative of amiloride, 5'betaenzylglycinyl-amiloride, was found to induce caspaseindependent necroptotic glioma cell death mediated by AIF and independent of PARP and H2AX activation (68). The AMP-activated protein kinase (AMPK) inhibitor compound $C$ has also been shown to induce necroptosis in glioma cells (69). These studies suggest that necroptosis represents a novel therapeutic target for brain tumors.

\section{Implication of necroptosis in cerebrovascular disease}

Cerebrovascular disease or cerebral vascular disorders (CVDs) are a group of brain dysfunctions related to disease of the blood vessels supplying the brain that can be generally classified as ischemic and hemorrhagic diseases. Endovascular treatment has emerged as a minimally invasive approach to treat cerebrovascular disease (70). The most common type of cerebrovascular disease is stroke, which is the second leading cause of death worldwide (71). Stroke commonly results in irreversible neuronal death and subsequent poor prognosis. Ischemic brain injury is associated with induction of necroptosis in the absence of intracellular apoptotic signaling (15). Necroptosis is an important cell death pathway involved in cerebral ischemia/ reperfusion injury. The administration of the necroptosis inhibitor necrostatin-1 alone or in combination with the apoptosis inhibitor Gly(14)-humanin was shown to have protective effects on oxygen-glucose deprivation-induced cell death (72). Moreover, combined treatment with the two inhibitors improved neurological scores and decreased infarct volume in mice after cerebral artery occlusion and reperfusion (72). 3-Methyladenine (3-MA), a widely used autophagy inhibitor, was observed to prevent severe global cerebral ischemia-induced programmed necrosis of hippocampal rat CA1 neurons (73).

$\mathrm{ICH}$ is an increasingly prevalent and devastating subtype of stroke with high rates of morbidity and mortality (74). Necroptosis has been suggested to participate in $\mathrm{ICH}-$ related cell death (19). Using an animal model, King et al. (19) reported that the necroptosis inhibitor necrostatin-1 can limit cell death, reduce hematoma volume, and improve neurobehavioral outcomes after $\mathrm{ICH}$. Chang et al. (75) reported that the inhibitor necrostatin-1 can also suppress apoptotic and autophagic pathway to exert neuroprotective effects in a mouse model of $\mathrm{ICH}$.

\section{Induction of necroptosis in neurons by 24(S)-hydroxycholesterol}

The brain is a cholesterol-rich organ and contains about $25 \%$ of the total amount of cholesterol in the body (76). Normally, brain cholesterol is prevented from entering into systemic circulation by the blood-brain barrier. Hydroxylation of cholesterol to generate 24(S)-hydroxycholesterol is critical to maintain brain cholesterol homeostasis, as 24(S)-hydroxycholesterol can cross the blood-brain barrier and be delivered to the liver (77). It has been reported that 24(S)-hydroxycholesterol induces necroptosis in neuronal cells that do not express caspase-8 (17). Yamanaka et al. (78) further reported that 24(S)-hydroxycholesterol-induced necroptosis is dependent on the activity of acyl-CoA: cholesterol acyltransferase 1 . Caspase- 8 has shown to inhibit necroptosis mediated by RIPK1 and RIPK3 (79). Therefore, necroptosis represents an important cell death mechanism in caspase-8-deficient cells.

\section{Conclusions}

Necroptosis is an alternative form of cell death that can be triggered by a variety of external stimuli, especially in the absence of apoptosis signaling. The MLKL-RIP1-RIP3 necrosome complex plays a critical role in the initiation of necroptotic cell death. Necroptosis is implicated in the pathogenesis of many diseases including neurosurgical 
conditions. Accumulating evidence shows that genetic and pharmacological inhibition of necroptotic signaling can confer neuroprotection after brain injury, therefore representing a promising therapeutic target. The development of small molecules that can control necroptosis is of clinical significance for preventing and treating neurosurgical diseases.

\section{References}

1. Healy E, Dempsey M, Lally C, Ryan MP. Apoptosis and necrosis: mechanisms of cell death induced by cyclosporine A in a renal proximal tubular cell line. Kidney Int 1998; 54: 1955-1966, doi: 10.1046/j.1523-1755.1998.00202.x.

2. Vanden Berghe $T$, Linkermann A, Jouan-Lanhouet S, Walczak $\mathrm{H}$, Vandenabeele P. Regulated necrosis: the expanding network of non-apoptotic cell death pathways. Nat Rev Mol Cell Biol 2014; 15: 135-147, doi: 10.1038/nrm3737.

3. Vanlangenakker $\mathrm{N}$, Vanden Berghe $\mathrm{T}$, Vandenabeele $\mathrm{P}$. Many stimuli pull the necrotic trigger, an overview. Cell Death Differ 2012; 19: 75-86, doi: 10.1038/cdd.2011.164.

4. Kaczmarek A, Vandenabeele P, Krysko DV. Necroptosis: the release of damage-associated molecular patterns and its physiological relevance. Immunity 2013; 38: 209-223, doi: 10.1016/j.immuni.2013.02.003.

5. Degterev A, Hitomi J, Germscheid M, Ch'en IL, Korkina O, Teng $X$, et al. Identification of RIP1 kinase as a specific cellular target of necrostatins. Nat Chem Biol 2008; 4: 313321, doi: 10.1038/nchembio.83.

6. Holler N, Zaru R, Micheau O, Thome M, Attinger A, Valitutti S, et al. Fas triggers an alternative, caspase-8-independent cell death pathway using the kinase RIP as effector molecule. Nat Immunol 2000; 1: 489-495, doi: 10.1038/82732.

7. Feng S, Yang Y, Mei Y, Ma L, Zhu DE, Hoti N, et al. Cleavage of RIP3 inactivates its caspase-independent apoptosis pathway by removal of kinase domain. Cell Signal 2007; 19: 20562067, doi: 10.1016/j.cellsig.2007.05.016.

8. Newton K, Dugger DL, Wickliffe KE, Kapoor N, de Almagro $M C$, Vucic D, et al. Activity of protein kinase RIPK3 determines whether cells die by necroptosis or apoptosis. Science 2014; 343: 1357-1360, doi: 10.1126/science.1249361.

9. Saeed WK, Jun DW. Necroptosis: an emerging type of cell death in liver diseases. World J Gastroenterol 2014; 20: 12526-12532, doi: 10.3748/wjg.v20.i35.12526.

10. Zhou W, Yuan J. Necroptosis in health and diseases. Semin Cell Dev Biol 2014; 35: 14-23, doi: 10.1016/j.semcdb.2014.07. 013.

11. Jouan-Lanhouet S, Riquet F, Duprez L, Vanden Berghe T, Takahashi N, Vandenabeele P. Necroptosis, in vivo detection in experimental disease models. Semin Cell Dev Biol 2014; 35: 2-13, doi: 10.1016/j.semcdb.2014.08.010.

12. Linkermann A, Hackl MJ, Kunzendorf $U$, Walczak $H$, Krautwald S, Jevnikar AM. Necroptosis in immunity and ischemia-reperfusion injury. Am J Transplant 2013; 13: 27972804, doi: 10.1111/ajt.12448.

13. Challa S, Chan FK. Going up in flames: necrotic cell injury and inflammatory diseases. Cell Mol Life Sci 2010; 67: 3241-3253, doi: 10.1007/s00018-010-0413-8.

14. Dmitriev YV, Minasian SM, Demchenko EA, Galagudza MM. Study of cardioprotective effects of necroptosis inhibitors on

\section{Acknowledgments}

This research was supported by the National Natural Science Foundation of China (\#81070988 and \#81171166) and Science and Technology Committee of Shanghai (\#0852nm04900, \#11nm0503200, and \#11JC1408602).

isolated rat heart subjected to global ischemia-reperfusion Bull Exp Biol Med 2013; 155: 245-248, doi: 10.1007/s10517013-2124-2.

15. Koshinuma S, Miyamae M, Kaneda K, Kotani J, Figueredo VM. Combination of necroptosis and apoptosis inhibition enhances cardioprotection against myocardial ischemiareperfusion injury. J Anesth 2014; 28: 235-241, doi: 10.1007/ s00540-013-1716-3.

16. Li Y, Yang X, Ma C, Qiao J, Zhang C. Necroptosis contributes to the NMDA-induced excitotoxicity in rat's cultured cortical neurons. Neurosci Lett 2008; 447: 120-123, doi: 10.1016/ j.neulet.2008.08.037.

17. Yamanaka K, Saito $\mathrm{Y}$, Yamamori T, Urano $\mathrm{Y}$, Noguchi N. 24(S)-hydroxycholesterol induces neuronal cell death through necroptosis, a form of programmed necrosis. $J$ Biol Chem 2011; 286: 24666-24673, doi: 10.1074/jbc.M111.236273.

18. Degterev A, Huang Z, Boyce M, Li Y, Jagtap P, Mizushima N, et al. Chemical inhibitor of nonapoptotic cell death with therapeutic potential for ischemic brain injury. Nat Chem Biol 2005; 1: 112-119, doi: 10.1038/nchembio711.

19. King MD, Whitaker-Lea WA, Campbell JM, Alleyne CH Jr, Dhandapani KM. Necrostatin-1 reduces neurovascular injury after intracerebral hemorrhage. Int J Cell Biol 2014; 2014: 495817, doi: 10.1155/2014/495817.

20. Zhong CQ, Li Y, Yang D, Zhang N, Xu X, Wu Y, et al. Quantitative phosphoproteomic analysis of RIP3-dependent protein phosphorylation in the course of TNF-induced necroptosis. Proteomics 2014; 14: 713-724, doi: 10.1002/pmic.2013 00326.

21. Wilson NS, Dixit V, Ashkenazi A. Death receptor signal transducers: nodes of coordination in immune signaling networks. Nat Immunol 2009; 10: 348-355, doi: 10.1038/ ni.1714.

22. Chan FK, Chun HJ, Zheng L, Siegel RM, Bui KL, Lenardo MJ. A domain in TNF receptors that mediates ligand-independent receptor assembly and signaling. Science 2000; 288: 23512354, doi: 10.1126/science.288.5475.2351.

23. Deveraux QL, Roy N, Stennicke HR, Van Arsdale T, Zhou Q, Srinivasula SM, et al. IAPs block apoptotic events induced by caspase-8 and cytochrome $c$ by direct inhibition of distinct caspases. EMBO J 1998; 17: 2215-2223, doi: 10.1093/emboj/ 17.8.2215.

24. Vanlangenakker $\mathrm{N}$, Vanden Berghe $\mathrm{T}$, Bogaert $\mathrm{P}$, Laukens $\mathrm{B}$, Zobel K, Deshayes K, et al. clAP1 and TAK1 protect cells from TNF-induced necrosis by preventing RIP1/RIP3-dependent reactive oxygen species production. Cell Death Differ 2011; 18: 656-665, doi: 10.1038/cdd.2010.138.

25. Morioka S, Broglie P, Omori E, Ikeda Y, Takaesu G, Matsumoto $\mathrm{K}$, et al. TAK1 kinase switches cell fate from apoptosis to necrosis following TNF stimulation. J Cell Biol 
2014; 204: 607-623, doi: 10.1083/jcb.201305070.

26. Hitomi J, Christofferson DE, Ng A, Yao J, Degterev A, Xavier $R J$, et al. Identification of a molecular signaling network that regulates a cellular necrotic cell death pathway. Cell 2008; 135: 1311-1323, doi: 10.1016/j.cell.2008.10.044.

27. Christofferson DE, Yuan J. Necroptosis as an alternative form of programmed cell death. Curr Opin Cell Biol 2010; 22: 263-268, doi: 10.1016/j.ceb.2009.12.003.

28. He S, Wang L, Miao L, Wang T, Du F, Zhao L, et al. Receptor interacting protein kinase-3 determines cellular necrotic response to TNF-alpha. Cell 2009; 137: 1100-1111, doi: 10.1016/j.cell.2009.05.021.

29. Li L, Chen W, Liang Y, Ma H, Li W, Zhou Z, et al. The Gbetagamma-Src signaling pathway regulates TNFinduced necroptosis via control of necrosome translocation. Cell Res 2014; 24: 417-432, doi: 10.1038/cr.2014.17.

30. Christofferson DE, Li Y, Yuan J. Control of life-or-death decisions by RIP1 kinase. Annu Rev Physiol 2014; 76: 129150, doi: 10.1146/annurev-physiol-021113-170259.

31. Shulga N, Pastorino JG. GRIM-19-mediated translocation of STAT3 to mitochondria is necessary for TNF-induced necroptosis. J Cell Sci 2012; 125: 2995-3003, doi: 10.1242/ jcs.103093.

32. Upton JW, Kaiser WJ, Mocarski ES. Virus inhibition of RIP3dependent necrosis. Cell Host Microbe 2010; 7: 302-313, doi: 10.1016/j.chom.2010.03.006.

33. Narayan N, Lee IH, Borenstein R, Sun J, Wong R, Tong G, et al. The NAD-dependent deacetylase SIRT2 is required for programmed necrosis. Nature 2012; 492: 199-204, doi: 10.1038/nature11700.

34. Lim SY, Davidson SM, Mocanu MM, Yellon DM, Smith CC. The cardioprotective effect of necrostatin requires the cyclophilin-D component of the mitochondrial permeability transition pore. Cardiovasc Drugs Ther 2007; 21: 467-469, doi: 10.1007/s10557-007-6067-6.

35. Moriwaki K, Chan FK. RIP3: a molecular switch for necrosis and inflammation. Genes Dev 2013; 27: 1640-1649, doi: 10.1101/gad.223321.113.

36. Sun L, Wang H, Wang Z, He S, Chen S, Liao D, et al. Mixed lineage kinase domain-like protein mediates necrosis signaling downstream of RIP3 kinase. Cell 2012; 148: 213-227, doi: 10.1016/j.cell.2011.11.031.

37. Murphy JM, Czabotar PE, Hildebrand JM, Lucet IS, Zhang JG, Alvarez-Diaz S, et al. The pseudokinase MLKL mediates necroptosis via a molecular switch mechanism. Immunity 2013; 39: 443-453, doi: 10.1016/j.immuni.2013.06.018.

38. Kaiser WJ, Sridharan H, Huang C, Mandal P, Upton JW, Gough PJ, et al. Toll-like receptor 3-mediated necrosis via TRIF, RIP3, and MLKL. J Biol Chem 2013; 288: 3126831279, doi: 10.1074/jbc.M113.462341.

39. Kim SJ, Li J. Caspase blockade induces RIP3-mediated programmed necrosis in Toll-like receptor-activated microglia. Cell Death Dis 2013; 4: e716, doi: 10.1038/cddis.2013.238.

40. Schworer SA, Smirnova II, Kurbatova I, Bagina U, Churova M, Fowler T, et al. Toll-like receptor-mediated down-regulation of the deubiquitinase cylindromatosis (CYLD) protects macrophages from necroptosis in wild-derived mice. $\mathrm{J}$ Biol Chem 2014; 289: 14422-14433, doi: 10.1074/jbc.M114.547547.

41. Lin Y, Choksi S, Shen HM, Yang QF, Hur GM, Kim YS, et al. Tumor necrosis factor-induced nonapoptotic cell death requires receptor-interacting protein-mediated cellular reactive oxygen species accumulation. J Biol Chem 2004; 279: 1082210828, doi: 10.1074/jbc.M313141200.

42. Kamata H, Honda S, Maeda S, Chang L, Hirata H, Karin M Reactive oxygen species promote TNFalpha-induced death and sustained JNK activation by inhibiting MAP kinase phosphatases. Cell 2005; 120: 649-661, doi: 10.1016/j.cell. 2004.12.041.

43. Leist $M$, Single $B$, Castoldi AF, Kuhnle $S$, Nicotera $P$. Intracellular adenosine triphosphate (ATP) concentration: a switch in the decision between apoptosis and necrosis. J Exp Med 1997; 185: 1481-1486, doi: 10.1084/jem.185.8.1481.

44. Los M, Mozoluk M, Ferrari D, Stepczynska A, Stroh C, Renz $A$, et al. Activation and caspase-mediated inhibition of PARP: a molecular switch between fibroblast necrosis and apoptosis in death receptor signaling. Mol Biol Cell 2002; 13: 978-988, doi: $10.1091 / \mathrm{mbc} .01-05-0272$.

45. Kroemer G, Galluzzi L, Brenner C. Mitochondrial membrane permeabilization in cell death. Physiol Rev 2007; 87: 99-163, doi: 10.1152/physrev.00013.2006.

46. Boujrad H, Gubkina O, Robert N, Krantic S, Susin SA. AlFmediated programmed necrosis: a highly regulated way to die. Cell Cycle 2007; 6: 2612-2619, doi: 10.4161/cc.6.21.4842.

47. Xu Y, Huang S, Liu ZG, Han J. Poly(ADP-ribose) polymerase-1 signaling to mitochondria in necrotic cell death requires RIP1/TRAF2-mediated JNK1 activation. J Biol Chem 2006; 281: 8788-8795, doi: 10.1074/jbc.M508135200.

48. Devalaraja-Narashimha K, Diener AM, Padanilam BJ. Cyclophilin $D$ gene ablation protects mice from ischemic renal injury. Am J Physiol Renal Physiol 2009; 297: F749F759, doi: 10.1152/ajprenal.00239.2009.

49. Zhivotovsky B, Galluzzi L, Kepp O, Kroemer G. Adenine nucleotide translocase: a component of the phylogenetically conserved cell death machinery. Cell Death Differ 2009; 16: 1419-1425, doi: 10.1038/cdd.2009.118.

50. Schinzel AC, Takeuchi O, Huang Z, Fisher JK, Zhou Z, Rubens $\mathrm{J}$, et al. Cyclophilin $\mathrm{D}$ is a component of mitochondrial permeability transition and mediates neuronal cell death after focal cerebral ischemia. Proc Natl Acad Sci U S A 2005; 102: 12005-12010, doi: 10.1073/pnas.0505294102.

51. Huai J, Vogtle FN, Jockel L, Li Y, Kiefer T, Ricci JE, et al. TNFalpha-induced lysosomal membrane permeability is downstream of MOMP and triggered by caspase-mediated NDUFS1 cleavage and ROS formation. J Cell Sci 2013; 126: 4015-4025, doi: 10.1242/jcs. 129999.

52. Vanden Berghe T, Vanlangenakker N, Parthoens E, Deckers W, Devos M, Festjens N, et al. Necroptosis, necrosis and secondary necrosis converge on similar cellular disintegration features. Cell Death Differ 2010; 17: 922-930, doi: 10.1038/ cdd.2009.184.

53. Suffys $P$, Beyaert R, De Valck D, Vanhaesebroeck B, Van Roy F, Fiers W. Tumour-necrosis-factor-mediated cytotoxicity is correlated with phospholipase-A2 activity, but not with arachidonic acid release per se. Eur J Biochem 1991; 195: 465-475, doi: 10.1111/j.1432-1033.1991.tb15727.x.

54. Kim WH, Choi CH, Kang SK, Kwon CH, Kim YK. Ceramide induces non-apoptotic cell death in human glioma cells. Neurochem Res 2005; 30: 969-979, doi: 10.1007/s11064005-6223-y.

55. Thon L, Mohlig H, Mathieu S, Lange A, Bulanova E, WinotoMorbach S, et al. Ceramide mediates caspase-independent programmed cell death. FASEB J 2005; 19: 1945-1956, doi: 
10.1096/fj.05-3726com.

56. Ma J, You C, Ma L, Huang S. Is decompressive craniectomy useless in severe traumatic brain injury? Crit Care 2011; 15: 193, doi: 10.1186/cc10358.

57. Algattas $\mathrm{H}$, Huang $\mathrm{JH}$. Traumatic Brain Injury pathophysiology and treatments: early, intermediate, and late phases post-injury. Int J Mol Sci 2014; 15: 309-341, doi: 10.3390/ ijms15010309.

58. You Z, Savitz SI, Yang J, Degterev A, Yuan J, Cuny GD, et al. Necrostatin-1 reduces histopathology and improves functional outcome after controlled cortical impact in mice. J Cereb Blood Flow Metab 2008; 28: 1564-1573, doi: 10.1038/jcbfm.2008.44.

59. Erlich S, Alexandrovich A, Shohami E, Pinkas-Kramarski R. Rapamycin is a neuroprotective treatment for traumatic brain injury. Neurobiol Dis 2007; 26: 86-93, doi: 10.1016/ j.nbd.2006.12.003

60. Chen S, Atkins CM, Liu CL, Alonso OF, Dietrich WD, Hu BR. Alterations in mammalian target of rapamycin signaling pathways after traumatic brain injury. J Cereb Blood Flow Metab 2007; 27: 939-949.

61. Park J, Zhang J, Qiu J, Zhu X, Degterev A, Lo EH, et al. Combination therapy targeting Akt and mammalian target of rapamycin improves functional outcome after controlled cortical impact in mice. J Cereb Blood Flow Metab 2012; 32: 330-340, doi: 10.1038/jcbfm.2011.131.

62. Liu Q, Qiu J, Liang M, Golinski J, van Leyen K, Jung JE, et al. Akt and mTOR mediate programmed necrosis in neurons. Cell Death Dis 2014; 5: e1084, doi: 10.1038/cddis.2014.69.

63. Lwin Z, MacFadden D, Al-Zahrani A, Atenafu E, Miller BA, Sahgal A, et al. Glioblastoma management in the temozolomide era: have we improved outcome? J Neurooncol 2013; 115: 303-310, doi: 10.1007/s11060-013-1230-3.

64. Han W, Xie J, Li L, Liu Z, Hu X. Necrostatin-1 reverts shikonin-induced necroptosis to apoptosis. Apoptosis 2009; 14: 674-686, doi: 10.1007/s10495-009-0334-x.

65. Huang $\mathrm{C}$, Luo $\mathrm{Y}$, Zhao J, Yang $\mathrm{F}$, Zhao $\mathrm{H}$, Fan $\mathrm{W}$, et al. Shikonin kills glioma cells through necroptosis mediated by RIP-1. PLoS One 2013; 8: e66326, doi: 10.1371/journal.pone.0066326.

66. Nomura $M$, Ueno A, Saga K, Fukuzawa M, Kaneda $Y$. Accumulation of cytosolic calcium induces necroptotic cell death in human neuroblastoma. Cancer Res 2014; 74: 1056-1066, doi: 10.1158/0008-5472.CAN-13-1283.

67. Coupienne I, Bontems S, Dewaele M, Rubio N, Habraken Y, Fulda S, et al. NF-kappaB inhibition improves the sensitivity of human glioblastoma cells to 5 -aminolevulinic acid-based photodynamic therapy. Biochem Pharmacol 2011; 81: 606616, doi: 10.1016/j.bcp.2010.12.015

68. Pasupuleti N, Leon L, Carraway KL III, Gorin F. 5Benzylglycinyl-amiloride kills proliferating and nonproliferating malignant glioma cells through caspase-independent necroptosis mediated by apoptosis-inducing factor. J Pharmacol Exp Ther 2013; 344: 600-615, doi: 10.1124/jpet.112.200519.

69. Liu X, Chhipa RR, Nakano I, Dasgupta B. The AMPK inhibitor compound $\mathrm{C}$ is a potent AMPK-independent antiglioma agent. Mol Cancer Ther 2014; 13: 596-605, doi: 10.1158/1535-7163.MCT-13-0579.

70. Broessner G, Beer R, Lackner P, Helbok R, Fischer M, Pfausler B, et al. Prophylactic, endovascularly based, longterm normothermia in ICU patients with severe cerebrovascular disease: bicenter prospective, randomized trial. Stroke 2009; 40: e657-e665, doi: 10.1161/STROKEAHA.109.557652.

71. Mathers CD, Boerma T, Ma FD. Global and regional causes of death. Br Med Bull 2009; 92: 7-32, doi: 10.1093/bmb/ Idp028.

72. Xu X, Chua KW, Chua CC, Liu CF, Hamdy RC, Chua BH. Synergistic protective effects of humanin and necrostatin-1 on hypoxia and ischemia/reperfusion injury. Brain Res 2010; 1355: 189-194, doi: 10.1016/j.brainres.2010.07.080.

73. Wang JY, Xia Q, Chu KT, Pan J, Sun LN, Zeng B, et al. Severe global cerebral ischemia-induced programmed necrosis of hippocampal CA1 neurons in rat is prevented by 3-methyladenine: a widely used inhibitor of autophagy. J Neuropathol Exp Neurol 2011; 70: 314-322, doi: 10.1097/ NEN.0b013e31821352bd.

74. Gong Y, Hua Y, Keep RF, Hoff JT, Xi G. Intracerebral hemorrhage: effects of aging on brain edema and neurological deficits. Stroke 2004; 35: 2571-2575, doi: 10.1161/ 01.STR.0000145485.67827.d0.

75. Chang $\mathrm{P}$, Dong $\mathrm{W}$, Zhang $\mathrm{M}$, Wang $Z$, Wang $\mathrm{Y}$, Wang $\mathrm{T}$, et al. Anti-necroptosis chemical necrostatin-1 can also suppress apoptotic and autophagic pathway to exert neuroprotective effect in mice intracerebral hemorrhage model. $J$ Mol Neurosci 2014; 52: 242-249, doi: 10.1007/s12031-013-0132-3.

76. Bjorkhem I, Meaney S. Brain cholesterol: long secret life behind a barrier. Arterioscler Thromb Vasc Biol 2004; 24: 806-815, doi: 10.1161/01.ATV.0000120374.59826.1b.

77. Bjorkhem I, Andersson U, Ellis E, Alvelius G, Ellegard L, Diczfalusy $U$, et al. From brain to bile. Evidence that conjugation and omega-hydroxylation are important for elimination of 24S-hydroxycholesterol (cerebrosterol) in humans. J Biol Chem 2001; 276: 37004-37010, doi: 10.1074/jbc.M103828200.

78. Yamanaka K, Urano Y, Takabe W, Saito Y, Noguchi N Induction of apoptosis and necroptosis by 24(S)-hydroxycholesterol is dependent on activity of acyl-CoA:cholesterol acyltransferase 1. Cell Death Dis 2014; 5: e990, doi: 10.1038/cddis.2013.524.

79. O'Donnell MA, Perez-Jimenez E, Oberst A, Ng A, Massoumi $\mathrm{R}$, Xavier $\mathrm{R}$, et al. Caspase 8 inhibits programmed necrosis by processing CYLD. Nat Cell Biol 2011; 13: 1437-1442, doi: 10.1038/ncb2362. 